\section{SAT0438 PSORIATIC ARTHRITIS AND NODAL OSTEOARTHRITIS CAN BE DIFFERENTIATED USING HAND RADIOGRAPHS: A NOVEL METHOD}

S. Bahadur ${ }^{1}$, A. Zavareh ${ }^{2}$, C. Hughes ${ }^{3}$, R. Mandegaran ${ }^{3}$, S. Subesinghe ${ }^{3}$, B. Kirkham ${ }^{3} .{ }^{1}$ Rheumatology; ${ }^{2}$ Radiology; ${ }^{3}$ Guys and St Thomas Trust, London, United Kingdom

Background: One of the difficulties of rheumatology practice is the differentiation of Psoriatic Arthritis (PsA) and Nodal Osteoarthritis (NOA) in some patients with distal interphalangeal joint involvement. MRI and ultrasound imaging, have recently been demonstrated as inconclusive in some cases $(1,2)$. This differentiation is critical, as treatment for these debilitating conditions is completely different.

Objectives: To establish a scoring system of radiographic joint and soft tissue features to differentiate PsA from NOA.

Methods: We devised a scoring system for hand radiographs of interphalangeal joints, soft tissue and bone features, allocated major and minor weighting. The scoring system was then tested in a single blind analysis of hand radiographs from 48 patients with PsA, 50 with NOA and 1 with RA (incorrectly classified as PsA at study entry) seen between 2008 and 2016. Anonymised patient images were assessed by a Musculoskeletal (MSK) Radiologist, blind to clinical information. Radiological diagnosis was then compared with clinical diagnosis. We taught the method to 2 rheumatology and 1 radiology trainees over 1 hour, who then independently assessed the same radiographs.

Results: The MSK radiologist reported normal hand radiographs in 5 patient sets. Of the remaining 94 patient sets, the scoring system correctly allocated $100 \%$ of images into PsA, NOA or RA. Notably, 2 patients with NOA who subsequently developed PsA several years later, and 1 patient with seropositive RA, initially misclassified as PsA, were correctly identified by the MSK radiologist.

Trainees using the system also achieved good agreement, after removing radiographs assessed as normal; Rheumatology trainees: $88 \%$ and $67 \%$ correct; Radiology trainee: $70 \%$ correct.

Conclusions: This initial single-centre study shows our novel radiological scoring system is effective at differentiating patients with PsA from NOA. Radiographs provide an accurate, time-efficient (for both clinician and patient) and inexpensive test. We also show that trainees can learn this scoring system with moderate accuracy after a short educational programme. We are currently carrying out a detailed analysis of the scoring system to optimise accuracy and ease of use by non-radiologists.

References:

[1] McGonagle D, Hermann KG, Tan AL. Differentiation between osteoarthritis and psoriatic arthritis: implications for pathogenesis and treatment in the biologic therapy era. Rheumatology. 2015;54:29-38.

[2] Yumusakhuylu $Y$, Kasapoglu-Gunal E, Murat $S$ et al. A preliminary study showing that ultrasonography cannot differentiate between psoriatic arthritis and nodal osteoarthritis based on enthesopathy scores. Rheumatology. 2016; 55:1703-4.

Disclosure of Interest: None declared

DOI: 10.1136/annrheumdis-2017-eular.6350

\section{SAT0439 INTEGRATED SAFETY SUMMARY OF TOFACITINIB IN PSORIATIC ARTHRITIS CLINICAL STUDIES}

G. Burmester ${ }^{1}$, O. FitzGerald ${ }^{2}$, K. Winthrop ${ }^{3}$, G. Williams ${ }^{4}$, V.F. Azevedo ${ }^{5}$, W.F.C. Rigby ${ }^{6}$, K. Kanik ${ }^{7}$, C. Wang ${ }^{7}$, P. Biswas ${ }^{8}$, T. Jones ${ }^{9}$, S. Menon ${ }^{7}$, N. Palmetto ${ }^{8}$, R. Rojo ${ }^{7} .{ }^{7}$ Charité - University Medicine Berlin, Berlin, Germany; ${ }^{2}$ Department of Rheumatology, St. Vincent's University Hospital, Dublin, Ireland; ${ }^{3}$ Oregon Health and Science University, Portland, OR; ${ }^{4}$ Williams Cancer Drug Consulting LLC, Wayne, NJ, United States; ${ }^{5}$ Universidade Federal do Paraná, Curitiba, Brazil: ${ }^{6}$ Geisel School of Medicine at Dartmouth, Lebanon, $\mathrm{NH}:{ }^{7}$ Pfizer Inc, Groton, CT; ${ }^{8}$ Pfizer Inc, New York, NY; ${ }^{9}$ Pfizer Inc, Collegeville, PA, United States

Background: Tofacitinib is an oral Janus kinase inhibitor under investigation for psoriatic arthritis (PsA).

Objectives: To describe the safety profile of tofacitinib from integrated Phase (P) 3 and long-term extension (LTE) studies.

Methods: Data were analysed for patients (pts) who received $\geq 1$ dose of tofacitinib 5 or $10 \mathrm{mg}$ BID or placebo (PBO), integrated across $2 \mathrm{P} 3$ studies (OPAL Broaden [12 months; NCT01877668]; OPAL Beyond [6 months; NCT01882439]) and 1 LTE study (OPAL Balance [ongoing, database not locked; NCT01976364]). Common adverse events (AEs; occurring in $\geq 2 \%$ of tofacitinib pts in any group) were analysed in the PBO-controlled portion (Months $0-3$ ) of the P3 studies (Cohort 1 [C1]). Serious AEs (SAEs) and discontinuations due to AEs were analysed over 12 months in pts randomised to tofacitinib 5 or $10 \mathrm{mg}$ BID in P3 studies (Cohort 2a [C2a]); pts randomised to PBO were excluded from this analysis. Deaths and AEs of special interest (serious infections [SI], herpes zoster $[\mathrm{HZ}]$, opportunistic infections [OI] including $\mathrm{HZ}$, major adverse cardiac events [MACE], malignancies, non-melanoma skin cancer [NMSC]) were evaluated in all tofacitinib-treated pts in the P3 and LTE studies (Cohort 3 [C3]). Incidence rates (IR; pts with events/100 pt-years [PY] and 95\% confidence intervals) are reported. Laboratory results will be reported in future publications.

Results: C1 included 474 tofacitinib- and 236 PBO-treated pts; C2a included 474 tofacitinib-treated pts; and C3 included 783 tofacitinib-treated pts (exposure:
776 PY). Nasopharyngitis (5.9\%) and headache (8.5\%) were the most commonly reported AEs at Month 3 in pts receiving tofacitinib 5 and $10 \mathrm{mg} \mathrm{BID,} \mathrm{respectively}$ (Table). In pts randomised to tofacitinib 5 or $10 \mathrm{mg} \mathrm{BID}$, over 12 months (C2a), the IRs for SAEs were $7.92(4.09,13.84)$ and $8.11(4.19,14.17)$, respectively. Discontinuation due to AEs occurred in $11(4.6 \%)$ and $11(4.7 \%)$ pts randomised to tofacitinib 5 and $10 \mathrm{mg} \mathrm{BID}$, respectively, with IRs of $7.16(3.58,12.82)$ and 7.31 $(3.65,13.08)$, respectively, over 12 months (C2a). Across all tofacitinib-treated pts in the P3 and LTE studies (C3), Sls occurred in 11 pts $(1.4 \%$; IR $1.40[0.70$, 2.50]). $\mathrm{HZ}$ was reported in 16 pts $(2.0 \%$; IR $2.05[1.17,3.33])$ receiving tofacitinib. All 3 cases of multidermatomal $\mathrm{HZ}$ were adjudicated as Ols; these were the only Ols $(0.4 \%$; IR $0.38[0.08,1.11])$. In C3, 2 deaths occurred $(0.3 \%$; IR $0.25[0.03$, $0.91]$ ); all were considered unrelated to the study drug. MACE were reported in 3 pts $(0.4 \%$; IR $0.38[0.08,1.11])$, malignancies (excluding NMSC) in 5 pts $(0.6 \%$; IR $0.63[0.21,1.48])$ and NMSC in 4 pts $(0.5 \%$; IR $0.51[0.14,1.30])$

Table: Common adverse events $(\geq 2 \%$ occurrence in any group, all causalities) at Month 3 in patients receiving tofacitinib 5 or $10 \mathrm{mg}$ BID or placebo

\begin{tabular}{|c|c|c|c|}
\hline $\begin{array}{l}\text { Common Adverse } \\
\text { Events, n (\%) }\end{array}$ & $\begin{array}{c}\text { Tofacitinib } \\
5 \text { mg BID } \\
(\mathrm{N}=238)\end{array}$ & $\begin{array}{c}\text { Tofacitinib } \\
10 \mathrm{mg} \text { BID } \\
(\mathrm{N}=236)\end{array}$ & $\begin{array}{l}\text { Placebo } \\
(\mathrm{N}=\mathbf{2 3 6}\end{array}$ \\
\hline Diarrhoea & $8(3.4)$ & $9(3.8)$ & $1(0.4)$ \\
\hline Dyspepsia & $5(2.1)$ & $2(0.8)$ & $2(0.8)$ \\
\hline Nausea & $6(2.5)$ & $5(2.1)$ & $7(3.0)$ \\
\hline Fatigue & 0 & $7(3.0)$ & $1(0.4)$ \\
\hline Bronchitis & $6(2.5)$ & $4(1.7)$ & 0 \\
\hline Nasopharyngitis & $14(5.9)$ & $13(5.5)$ & $6(2.5)$ \\
\hline Pharyngitis & $1(0.4)$ & $7(3.0)$ & $3(1.3)$ \\
\hline $\begin{array}{l}\text { Upper respiratory } \\
\text { tract infection }\end{array}$ & $12(5.0)$ & $11(4.7)$ & $11(4.7)$ \\
\hline Urinary tract infection & $3(1.3)$ & $6(2.5)$ & $5(2.1)$ \\
\hline Headache & $9(3.8)$ & $20(8.5)$ & $11(4.7)$ \\
\hline Dizziness & $6(2.5)$ & $1(0.4)$ & $3(1.3)$ \\
\hline Acne & $3(1.3)$ & $5(2.1)$ & 0 \\
\hline Hypertension & $4(1.7)$ & $5(2.1)$ & $3(1.3)$ \\
\hline
\end{tabular}

BID, twice daily; $\mathrm{N}$, number of patients evaluable

Conclusions: Tofacitinib was well tolerated in pts with PsA, with a safety profile consistent to that seen in RA; no new risks were identified. Longer-term follow-up and larger pt populations will provide further information on the safety profile of tofacitinib in pts with PsA.

Acknowledgements: These studies were sponsored by Pfizer Inc. Editorial support was provided by C Viegelmann of CMC and was funded by Pfizer Inc. Disclosure of Interest: G. Burmester Grant/research support from: UCB, Consultant for: AbbVie, Bristol-Myers Squibb, Eli Lilly, Hexal, Janssen, MSD, Medlmmune, Novartis, Pfizer Inc, Sanofi, Roche, Speakers bureau: AbbVie, Bristol-Myers Squibb, Hexal, MSD, Novartis, Pfizer Inc, Roche, O. FitzGerald Grant/research support from: AbbVie, Bristol-Myers Squibb, Consultant for: Bristol-Myers Squibb, Eli Lilly, Janssen, Pfizer Inc, Speakers bureau: Celgene, Janssen, Novartis, K. Winthrop Grant/research support from: Bristol-Myers Squibb, Pfizer Inc, Consultant for: AbbVie, Amgen, Bristol-Myers Squibb, Eli Lilly, Galapagos, Pfizer Inc, UCB, G. Williams Consultant for: Pfizer Inc, V. Azevedo Grant/research support from: Bristol-Myers Squibb, GSK, Pfizer Inc, UCB, Consultant for: AbbVie, Bristol-Myers Squibb, Janssen, Merck Novartis, Pfizer Inc, Serono, W. F. Rigby Grant/research support from: Amgen, Pfizer Inc, Roche, Consultant for: Bristol-Myers Squibb, Eli Lilly, Pfizer Inc, Roche, K. Kanik Shareholder of: Pfizer Inc, Employee of: Pfizer Inc, C. Wang Shareholder of: Pfizer Inc, Employee of: Pfizer Inc, P. Biswas Shareholder of: Pfizer Inc, Employee of: Pfizer Inc, T. Jones Shareholder of: Pfizer Inc, Employee of: Pfizer Inc, S. Menon Shareholder of: Pfizer Inc, Employee of: Pfizer Inc, N. Palmetto Shareholder of: Pfizer Inc, Employee of: Pfizer Inc, R. Rojo Shareholder of: Pfizer Inc, Employee of: Pfizer Inc

DOI: 10.1136/annrheumdis-2017-eular.1573

\section{SAT0440 DO DEPRESSION AND ANXIETY INFLUENCE THE CHANCE OF REMISSION IN PATIENTS WITH PSORIATIC ARTHRITIS? REAL LIFE DATA FROM THE NOR-DMARD STUDY}

B. Michelsen ${ }^{1}, 2$, E.K. Kristianslund ${ }^{1}$, K.M. Fageli ${ }^{1}$, E. Lie ${ }^{1}$, H.B. Hammer ${ }^{1}$, G. Haugeberg ${ }^{2,3}$, T.K. Kvien ${ }^{1} .{ }^{1}$ Dept. of Rheumatology, Diakonhjemmet Hospital, Oslo; ${ }^{2}$ Dept. of Rheumatology, Hospital of Southern Norway Trust, Kristiansand; ${ }^{3}$ Dept. of Rheumatology, Martina Hansens Hospital, Oslo, Norway

Background: Depression and anxiety are frequent comorbidities in psoriatic arthritis (PsA). Still, the potential influence of depression/anxiety on achievement of remission remains unexplored.

Objectives: To investigate the predictive value of baseline depression/anxiety on the likelihood of achieving remission in PsA, as well as the associations between 